\title{
Paideusis
}

\section{A Consideration of Bogdan's "A Taxonomy of Responses and Respondents to Literature"}

\section{Jill Paton Walsh}

Volume 3, Number 1, 1989

URI: https://id.erudit.org/iderudit/1073404ar

DOI: https://doi.org/10.7202/1073404ar

See table of contents

Publisher(s)

Canadian Philosophy of Education Society

ISSN

0838-4517 (print)

1916-0348 (digital)

Explore this journal

Cite this article

Walsh, J. (1989). A Consideration of Bogdan's "A Taxonomy of Responses and Respondents to Literature". Paideusis, 3(1), 5-10.

https://doi.org/10.7202/1073404ar 


\title{
A Consideration of Bogdan's "A Taxonomy of Responses and Respondents to Literature"
}

\author{
Jill Paton Walsh
}

Cambridge, England

In her complex and interesting article, ${ }^{1}$ Deanne Bogdan offers insights into three different types of interaction between text and reader. She calls the first "Total Form," which is characterized by a response called "stasis." The second she calls "Partial Form" which is associated with stock, kinetic, and spectator responses--all more or less defective. Finally, she proposes a second sort of "Total Form" which she thinks is more adequate than the first because it results in "autonomous response."

When literary theory is directed to the understanding and description of reader response, it offers in a way which, though rare in our culture, is, nevertheless, useful to practising writers. Knowledge of the nature of reader responses can illuminate the design of rhetorical devices in the work-in-progress. By contrast, the effect of older modes of literary theory focuses on readers, not writers, and separates the former from their own experience by its preoccupation with the analyses of literary rhetoric. If the naive reader cries "Wow!" like Rita before she was educated, or falls silent, stunned by stasis as by a lightning flash, while the trained reader produces a literary essay using the terms of the latest fashion in criticism, then even sophisticated writers are liable to hope for naive readers among their audience. One might also hope to catch educated readers off-guard, or hope to be read by very intelligent people at a time when they were not doing criticism, but simply reading. In a telling reference to Northrop Frye, Bogdan reminds us of "the virtual impossibility of simultaneously participating in and being consciously aware of experience."

This "dissociation of sensibility" applies to writers as well as to readers, and in a way represents the typical moral temptation of a writer's life. The typical temptation of a writer is to observe rather than undergo life, to turn life into material for writing, as critics then turn written words into material for criticism. When Damon Runyon said he had never met a boring person, we can perceive in the boast a sense in which he has not met the people whom he met. Or, as a clearer example, take the writer who fell down the stairwell of her apartment building in New York, ricocheting down floor after floor, breaking ribs and wrists ... as she went, she found herself saying "Ah!"

Bogdan is well aware of the possibility that this dissociation could be prevent a critical response to literature, that one could not at the same time do literary criticism and read. But she does not wish to concede this somewhat romantic position because, among the responses she catalogues, her favoured one, the autonomous response, involves a degree of detachment.

In outline, then, the taxonomy proposed by Bogdan goes as follows. There are two very different kinds of response called "Total Form"--stasis, and autonomous response. Then, under the heading "Partial Form," she places the more or less defective responses called the stock, kinetic, and spectator.

First, let us consider stasis which is a lightning flash response, an admired, and hoped for instantaneous reaction of pleasure, as the form and content 
of a literary work are apprehended in the same moment in their entirety. According to Bogdan, such moments of perfect apprehension are partly dependent on the sense of difference, of "un-lifelike-ness" of a literary text. Stasis is a primitive response to be prized but not directly to be sought after.

I am willing to believe that a teacher cannot attempt to orchestrate the flash of illumination in the student; it happens or it does not and, when it does, it is perhaps best expressed by silence. However, it is clear that the stasis effect of the story Bogdan chooses as an example has been sought after by the author. The dark side of such moments of intense literary experience, Bogdan tells us, is their unreliability, brevity, and randomness. I would not myself use the word random of an effect so palpably designed by the author, so likely to recur in one reader after another. But "brevity" is certainly justified. In the sense described, stasis is surely available only on a first reading for it depends partly on surprise. A second reading may renew the pleasure leaning on memory of the first reading, but only absolutely total amnesia could allow the same reader to experience stasis in the story twice.

Bogdan specifically states that one must question stasis as a universal measure of literary value, but the very high value she puts on it nevertheless is at odds with two traditional parameters of literary merit. To value stasis so highly is to value first readings much more highly than subsequent readings. Further, to illustrate her discussion Bogdan provides us with a summary of the story The Painted Door, consisting of alternating passages of precis and of quotation, and this summary is fully adequate to equip us to follow her account of stasis. But it has been usual to associate literary merit precisely with what cannot be paraphrased; the poetry is what cannot be translated.

I am inclined to think that the traditional literary canon has been distorted by too much reliance on reactions to completed multiple readings considered in full retrospect. This tends to undervalue masterpieces of first reading like The Painted Door or Stevenson's The Genie in the Bottle; it tends to downgrade plot in general. Even so, there is an obvious danger that the lightning flash will short-circuit many possible sorts of literary meaning, illuminating in a way which is neat, slick even, which has exchanged the sudden brilliance for a capacity to cast a steady light on the messy contingencies of real life. Bogdan is well aware of the tension between elegant form and verisimilitude, and draws specific attention to it. The "formed" nature of a story like The Painted Door is what she seems to mean by her demand for literature to preserve a degree of difference from life in order to make possible the occurrence of stasis.

It seems to me that the contrast between "messy" realism and "tidy" realism (my terms) which Bogdan makes as she considers "Partial Form," illustrated by readers' responses to Updike's $A \& P$, is made more clearly if one contrasts fantasy and realism. Fantasy forces a metaphorical mode of understanding: there are no dragons in the world, but there is entrenched and vicious greed for treasure. Realism, which is grossly misread as documentary, permits itself to be so read by naive readers. I have made this point at length elsewhere ${ }^{2}$ and it seems to me equally valid when applied to different kinds of realism. Indeed, Bogdan's array of defective responses shows that two out of three of them go astray by failing to recognize the literary nature of the text, and reacting to it with real-life responses as though it were raw real life.

When we consider the responses categorised by Bogdan as "Partial 
Form," our attention is turned to examples of response to $A \& P$, though Bogdan points out that a stock response to The Painted Door would also be perfectly possible. A stock response, for example, would take the form of moral condemnation of the adulterous wife in the story, without any trace of sympathetic involvement in her struggle. This potential replacement of one example by the other sample text seems to me important, though made very briefly, and I shall return to it.

For the moment, I would like to offer some comment on Bogdan's definitions and examples of defective responses, those which she categorises as "Partial Form." First come positive and negative forms of stock response. A positive stock response to $A \& P$ takes the form of liking and sympathising with Sammy because the reader has been a check-out clerk, and readily imagines himself in the situation described. A negative stock response is to hate the story, because the hero is dislikable. In fact, readers are simply treating the story as though it were a happening in their own lives, and reacting as they would react. It is difficult to say exactly what is wrong with stock response as described by Bogdan. Certainly, the responses she quotes are inadequate, and have aborted a proper understanding of $A \& P$; it is obviously not helpful to "consider the story trivial or morally reprehensible ... as though Sammy were the boy next door rather than the author's fictive invention." But if Sammy were the boy next door, the reaction would likewise abort understanding and sympathy. And would it be wrong if a more sophisticated person were to say that they liked War and Peace because of the radiant portrayal of femininity in the characterisation of Natasha? Or if a murderer liked Crime and Punishment because the murderer in it is ultimately redeemed? The application of one's personal preferences and interests to literature as if it were life might assist rather than obstruct the enjoyment of a book. What is wrong with the responses quoted, it seems to me, is not so much that they are mindsets which obstruct reading, as that they are mindsets which are inadequate and would also obstruct life.

Bogdan's warning that "efforts to select literary works on the basis of their ready appeal to students' real life interests, problems and experience are often misguided" is well made, for to read well in the presence of this kind of relevance is a sophisticated skill. Any reader of Paideusis will know that literature is not relevant in the sense that Sammy is relevant to teen-age check-out clerks; it does not work by being particular, but by being general--relevant in the sense that Sammy is relevant to any other human being. And yet there is a paradox here. Works of literature are based on authors' lives. What else could they be based on? Readings of literature are made from the standpoint of readers' lives. What other standpoint is available? In rejecting crude in favour of sophisticated literary rhetoric, crude in favour of sophisticated responses, we do not entirely unlock this conundrum.

Even more baffling are the defective responses which Bogdan calls kinetic. Kinetic responders want emotional gratification. Bogdan cites the adrenalin flows stimulated by a thriller. The gratification of hunger for romance supplied by pulp love stories is a parallel. Bogdan's example, however, is one of the pleasure arising from recognition, which she likens to that afforded by "sitcoms".-."Aren't 19-year old boys exactly like that?" This seems to me already a substantially more sophisticated response than that of the reader who simply applies the text to a personal hunger for action, or for love, like someone 
scratching an itch, and appreciating relief, or complaining of the lack of it. Bogdan then delineates two or more forms of kinetic response--those of the idealogue and of the jaded predictor. The jaded predictor does not respond because he/she knows too much what to expect ("Not another Updike ending!" ). Bogdan tells us that "the problem is not that the response is insufficiently grounded in the text, but that the text remains a static body of words because the readers' feelings are not open to imaginative engagement." Literary knowledge militates against literary experience. It is interesting that Bogdan is at this point prepared to blame the weariness of the reader for the failure. She does not mention the possibility that the text might be at fault. I shall return to this point later.

The last kinetic responder, the idealogue, is well able to read a story right through, and discern a holistic meaning. The reader is rather good, in fact, at reading for the message, but not capable of considering the message so discerned except in terms of a rigid ideology pre-existing and unmodifiable at the time of the reading. Feminist readings are called in as examples, but there are many ideologies abroad in the world which have similar effects on reading.

I must admit that I do not find the classification of all the responses listed by Bogdan as kinetic particularly clear. It is very clear that all these responses are defective; but the defect is surely not organically related to the fact that they are all responses seeking gratification. Rather, in a situation where there is a hierarchy of gratifications, they are responses in search of cruder, or lower, pleasures. Even the most sophisticated reading must be kinetic, in some way-don't we all read for gratification at some level? Why else do we read?

Finally, we come to spectator response--often induced by teachers--which is a dry and rigid naming of parts, the relegation of literary experience to an occasion for doing criticism. The spectator response, Bogdan tells us "is uncommon in $A \& P$ because the natural tendency is to read the story in an engaged rather than in a detached mode." I shall return to this phrase.

In the closing section of her paper, Bogdan offers us an alternative route to a condition approximating stasis--an achievable alternative, which proceeds by a dialectic between engagement, or the participating response, and detachment or the critical response. Instead of waiting for the lightning stroke of stasis, the reader builds on the material available, passing through a pre-critical to a critical response, and finally achieving an autonomous response, "more valuable than stasis because it keep the flash of lightning striking in the same way and with the same intensity." In the end, we arrive at an expansion of insight, and a heightened sensibility to art and life.

This discussion has so far closely followed Bogdan's paper, but I would like now to offer some further thoughts. I am puzzled to know exactly where the responses we are discussing are located. Bogdan illustrates her point with citations which are seemingly chosen at random from one or other of her sample texts and from the words of readers. In spite of the carefully precise use of dozens of technical words which distance what she is saying from discourse which ordinary people might use to discuss what they have read, she seems to fail in rigour over this question. "What," she asks, "does the autonomous response look like in $A \& P$ ?" And this phrase short circuits an important question. It ought to read, "What does an autonomous response to $A \& P$ look like in a student's essay?" It may, of course, be true that a given literary text 
strongly tends to elicit certain patterns of response. Or perhaps it tends to inhibit certain responses, as when Bogdan tells us, "The spectator response is uncommon in $A$ \& $P$ because the natural tendency is to read the story in an engaged rather than a detached mode." But a natural tendency belongs surely to a reader rather than to a text.

The fact is that there is a hierarchy of readings. Some of the defective responses quoted by Bogdan are so inadequate that they belong to a pathology of reading rather than to a natural history of it. To be interested in them would necessarily involve being interested in the perpetrators of them, as people, as pupils perhaps. There is never anything wrong in being interested in people, but nothing interesting about the texts themselves can be learned by readings of such incompetence. Very highly competent readings, of course, can enlighten us and improve our own readings of literary texts. And somewhere in the hierarchy of reading is the one the author expected the reader to make. The inter-reaction of this designed reading with actual readings of more or less skill and adequacy is very interesting, but Bogdan does not seem concerned at all to include an author's intentions, conscious or subliminal, in her analysis. Yet it seems to me that only one reading is actually located in the text, and that is the one the author expected the reader to make. When the reader is able to make the expected reading, or an interesting variation of it, not too far from the expected track, a literary experience is conveyed. ${ }^{3}$ Following the expected track may involve a temporary setting aside of some or many aspects of the reader's personal peculiarities and beliefs, as in the case of the feminist confronted with $A \& P$. Many aspects of the author's personality and belief system have similarly been put in abeyance to allow the story to take the form we call fiction, and not a form we would call fable, sermon, lesson, and so on.

When the process works, we feel "taken out of ourselves"; we have been spell-bound into feeling and thinking "unselfishly" and we are rewarded with a glow not unlike that which follows on a self-abnegating action towards our fellow men. The high moral standing which literature enjoys very widely may arise in large part from this effect. Bogdan's decorous advocacy of an autonomous response is rightly made; if her taxonomy helps to direct the efforts of educators towards encouraging it, it is fully justified.

I have one last point to make about this discussion of responses. The responses quoted are all very broad brush, and both sample texts are short and simple, containing one episode. The problem for an author of fiction is to lead a reader down a complex track full of epiphanies and peripaties, and to guess what the reader will feel, when that reader will realise things, what that reader will wish to be told, and so on. Because it was of concern to the maker of the text while the text was in the making, detailed reader response during a reading really is imprinted in the text. Such detailed readings are seldom reported on, though as an author, I have been fortunate enough to have had one of my works subjected to such attention. ${ }^{4}$ I was able to learn much by comparing point-bypoint my expectations with my reader's.

A reading, not a reader, is implied in every work of fiction. Teaching people how to make many different implied readings really does teach them a dialectic, if not with heaven, at least with other human beings. 


\section{Notes}

1 Paideusis, 1(1), (Fall) 1987, 13-32.

2"The Art of Realism" printed in Celebrating Children's Books: Essays in Honour of Zena Sutherland, Betsey Heame and Marilyn Kaye (Eds.), (New York: Lothrop, Lee, \& Shepherd, 1981).

${ }^{3}$ An eccentric reading can, of course, be an improvement upon the normal reading, unfolding possibilities additional or superior to those of which the author was aware; unfortunately, these, too, will be lost for the next reader for they are not located in the text.

${ }^{4}$ Hugh Crago, "Readers in the Reader," Signal, 39, (September) 1982; and Jill Paton Walsh, "The Writers in the Writer: A reply to Hugh Crago," Signal, 40, (January) 1983. 